\title{
RANCANG BANGUN SPEED BUMP SEBAGAI PEMBANGKIT LISTRIK ENERGI ALTERNATIF
}

\author{
Aris Suryadi \\ Program Studi Teknologi Listrik \\ Politeknik Enjinering Indorama, Purwakarta, \\ Email: aris.suryadi@pei.ac.id \\ Emmanuel Agung Nugroho \\ Program Studi Mekatronika \\ Politeknik Enjinering Indorama, Purwakarta, \\ Email: emmanuel.agung@pei.ac.id \\ Purwandito Tulus Asmoro \\ Program Studi Teknologi Listrik \\ Politeknik Enjinering Indorama, Purwakarta, \\ Email: purwamdito@pei.ac.id
}

\begin{abstract}
ABSTRAK
Speed bump atau dalam bahasa Indonesia disebut "Polisi Tidur", dianggap kurang bermanfaat dan mengganggu bagi para pengendara motor untuk mengurangi kecepatan motornya. Muncul sebuah gagasan untuk merancang sebuah alat yang pada penerapannya dapat memanfaatkan sebagai pembangkit listrik dengan sumber penggerak generator dari polisi tidur. Dengan menggunakan rangkaian elektronika daya sebagai regulator dari keluaran yang dihasilkan. Metode penelitian dari alat ini adalah ketika kendaraan melewati speed bump maka akan menginjak bump yang dapat bergerak naik dan turun, kemudian gerakan dari naik dan turunnya bump tersebut diubah menjadi gerakan memutar generator. Tegangan yang dihasilkan dari generator tersebut disimpan pada accumulator yang nantinya energi listrik dapat difungsikan sesuai kebutuhan. Adapun yang menjadi tujuan dari penelitian ini adalah dapat menjadi sumber energi alternatif terbarukan sebagai penghasil listrik, dapat memanfaatkan energi yang terbuang menjadi energi yang potensial.
\end{abstract}

Kata kunci: speedbump; pembangkit listrik; accumulator.

\section{ABSTRACT}

Speed bump or in Indonesian language called "Polisi Tidur", is considered less useful and disturbing for motorcyclists to reduce the speed of their motorbikes. An idea arose to design a device, which in its application could be utilized as a power plant with a generator driving sourced from a speed bump. By using a power electronics circuit as a regulator of the output produced. The research method of this tool is that when a vehicle passes a speed bump it will step on a bump that can move up and down, then the movement of the rise and fall of the bump is converted into a circular motion generator. The voltage generated from the generator is stored in the accumulator which will be used as electrical energy as needed. The purpose of this research is to be able to become a source of renewable alternative energy as a producer of electricity, to be able to utilize wasted energy into potential energy.

Keyword: speed bump; power plants; accumulator.

\section{PENDAHULUAN}

Potensi energi baru dan terbarukan (EBT) Indonesia cukup besar, dengan variasi jenis energi yang beragam, akan tetapi potensi EBT tersebut belum optimal dikembangkan karena berbagai kendala penerapannya, seperti biaya investasi yang tinggi, effisiensi teknologi yang relatif rendah, letak geografis, dan faktor sosial masyarakat sebagai pengguna energi. Apabila semua kendaraan yang hilir mudik di jalan raya dapat dimanfaatkan potensi energi yang dimiliki dan dapat membangkitkan menjadi energi listrik, maka dengan mekanisme serta kebijakan yang mendukung akan potensi sebagai pembangkit energi listrik serta menjadi sumber energi yang tidak terpikirkan sebelumnya [1]. 
Pemanfaatan sebelumnya polisi tidur biasanya hanya sebatas memperlambat laju kendaraan agar terhindar dari kecelakaan. Seiring dengan pertambahan jumlah kendaraan yang sebanding dengan jumlah pertambahan penduduk yang melewati jalan. Upaya yang telah dilakukan salah satunya adalah dengan membuat kenyamanan pengemudi setelah melewati polisi tidur dengan mengoptimalkan bentuk dan ketinggian speed bump [2],[3].

Speed bump merupakan prototipe sistem tuas sebagai alat konversi energi mekanik menjadi energi listrik dengan memanfaatkan laju kendaraan pada bantalan (bump). Kendaraan yang melewati jalan raya akan menginjak bantalan (bump) yang terhubung dengan tuas dan pegas, freewheel, serta flywheel yang terhubung pada poros generator. Akibat putaran generator menghasilkan energi listrik. Daya keluaran pada generator disimpan pada accumulator selanjutnya daya listrik yang tersimpan dapat digunakan untuk penerangan jalan [4].

\section{LANDASAN TEORI}

\subsection{Hukum Keseimbangan}

Merupakan hubungan antara gaya yang bekerja pada suatu benda dan gerak yang disebabkannya. Dalam hukum Newton, gaya tekan kendaraan terhadap speed bump yang terjadi di jalan raya dimanfaatkan untuk menggerakan tuas [5],[6].

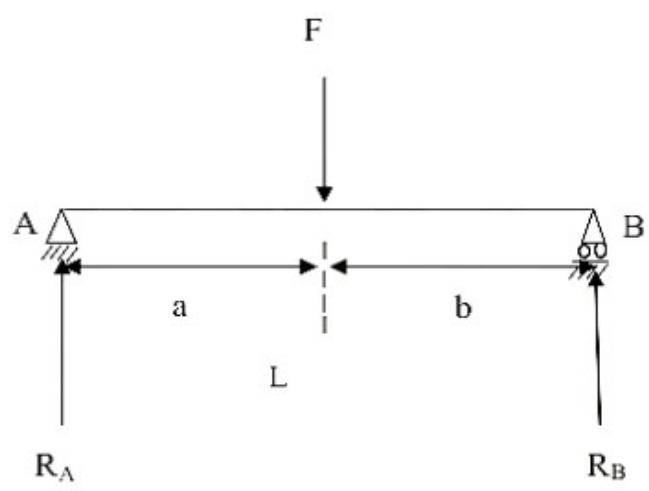

Gambar 1. Konsep Keseimbangan [9]

Rancangan pada rangka dirancang untuk mendukung beban dalam bentuk tertentu serta dan mengalami deformasi jika mengalami pembebanan. Struktur mengalami gaya eksternal serta reaksi pada titik pendukung strukturnya [7]. Semua gaya yang bekerja pada benda dianggap bekerja pada titik benda tersebut, dan jika gaya-gaya ini tidak seimbang. Daya listrik yang dihasilkan dari rancangan alat pembangkit listrik tenaga speed bump ini, dapat dinyatakan dengan persamaan sebagai berikut [8]:

$$
P=V . I
$$

atau

$$
P=I^{2}, R
$$

Keterangan :

$\mathrm{P}=$ Daya yang dihasilkan (watt)

$\mathrm{I}=$ Arus listrik (ampere)

$\mathrm{V}=$ Tegangan listrik (volt)

$\mathrm{R}=$ Hambatan $(\mathrm{ohm})$

\subsection{Hasil Perancangan Speed Bump}

Perancangan alat meliputi tata letak bagian dari komponen mekanik dan panel listrik. Adapun perancangan rangka pada speed bump diperlihatkan pada gambar 2. 


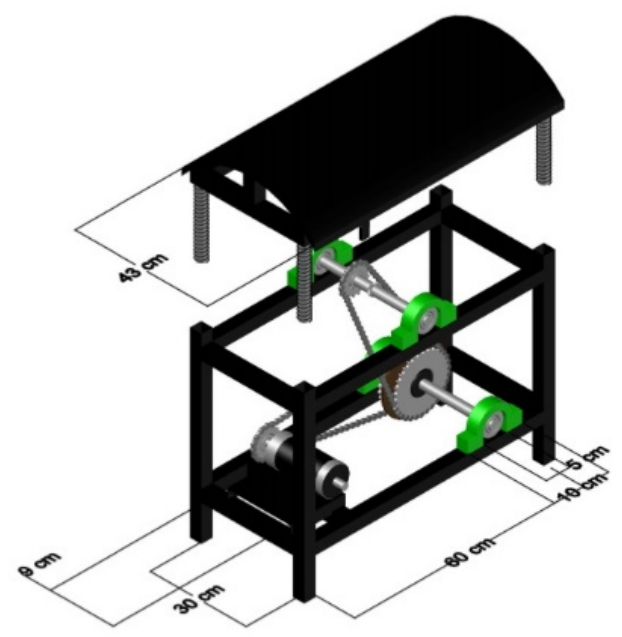

Gambar 2. Perancangan Speedbump

Sedangkan hasil perancangan speed bump termasuk dengan panel listrik terlihat pada gambar 3 .

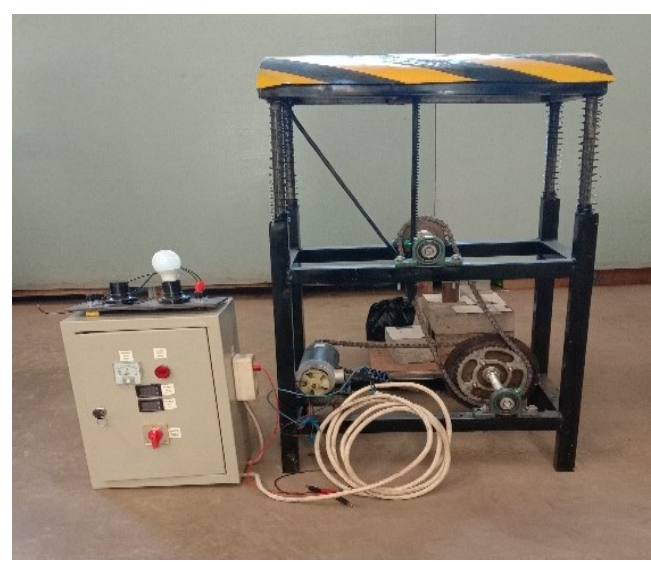

Gambar 3. Hasil Perancangan Speedbump

\subsection{Prinsip Kerja Speedbump}

Untuk menghasilkan listrik generator perlu diputar dengan kecepatan putaran tertentu, maka gerak naik turun dari speed bump diubah menjadi gerak memutar gear pada generator agar generator mampu menghasilkan energi listrik. Langkah gerak pada speed bump sebagai pembangkit listrik berawal dari gerak bump yang diinjak oleh sepeda motor yang melewati, lalu bump menggerakan rack gear yang merubah gerak linier menjadi putaran [9]. Adapun langkah gerak speed bump yang diinjak oleh sepeda motor terlihat pada gambar 4 .

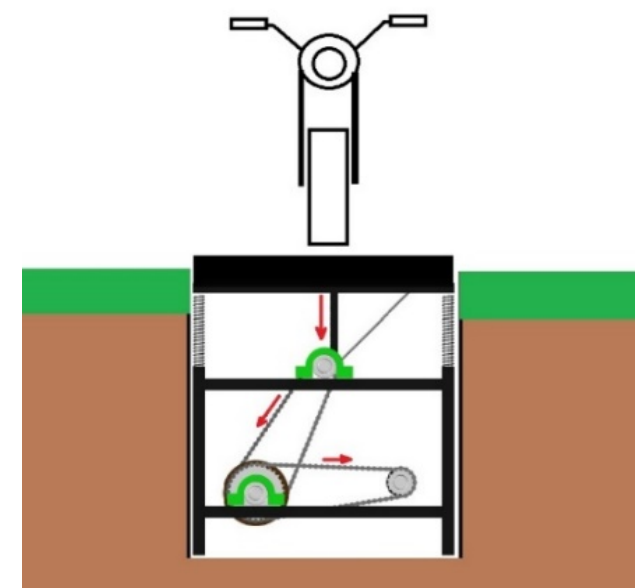

Gambar 4. Langkah Gerak Speedbump 
Energi listrik yang dihasilkan dari generator tidak konstan, karena setiap motor yang melewati kecepatannya tidak sama. Karena energi listrik yang dihasilkan dari generator masih kecil dan belum bisa digunakan untuk mengisi daya pada accumulator, maka harus dinaikkan dan disearahkan dengan rangkaian elektrik. Ketika tegangan sudah searah dan lebih dari $12 \mathrm{~V}$, maka dapat digunakan untuk mengisi daya pada accumulator. Untuk lebih jelasnya alur kerja sistem pada speed bump sebagai pembangkit listrik diperlihatkan pada gambar 4.

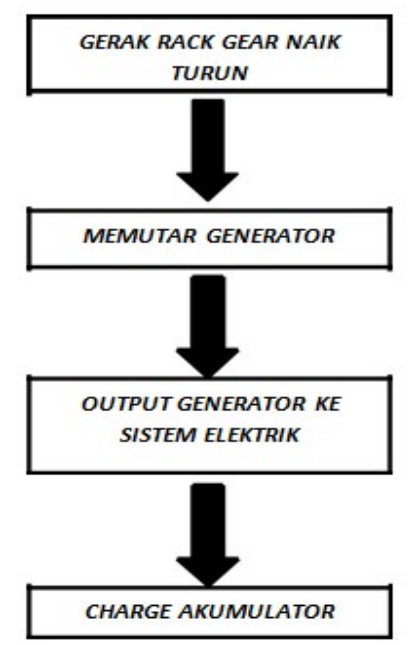

Gambar 4. Alur Kerja Sistem

\section{METODOLOGI PENELITIAN}

\subsection{Tahapan Penelitian}

Penelitian dimulai dengan mempelajari beberapa referensi dan literatur. Tahap kedua adalah merancang speed bump, menetukan kebutuhan rangkaian pengendali, inverter beserta pemilihan accumulator. Selanjutnya tahap ke tiga melakukan evaluasi rancangan pada sistem dilanjuti pada tahap ke empat melakukan pengukuran dan uji coba kelayakan perangkat, apakah telah sesuai dengan rancangan dan daya yang dihasilkan. Adapun alur metode penelitian dapat dilihat pada gambar 5 .

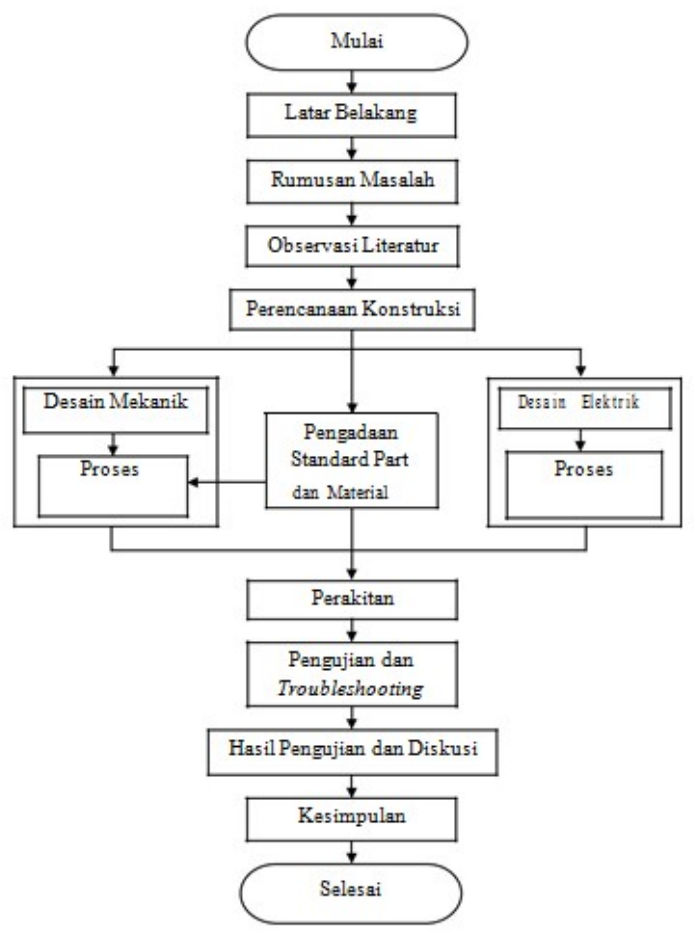

Gambar 5. Alur Metode Penelitian 
Perakitan alat yang telah dilakukan, selanjutnya melakukan pengujian pada alat. Pengujian alat jika mengalami kendala dan tidak sesuai dengan rencana awal maka dilakukan perbaikan pada titik yang menjadi kendala. Selanjutnya proses pengambilan data pengukuran putaran generator, tegangan serta fungsi kinerja alat. Setelah proses tersebut di atas dilakukanlah analisa data dan simpulan.

\subsection{Waktu dan Tempat Penelitian}

Dalam kurun waktu kurang lebih 5 (lima) bulan penelitian ini dimulai dari penandatangan kontrak penelitian. Pengujian dilakukan di lokasi samping laboratorium Prodi Teknologi Listrik, Politeknik Enjinering Indorama. Pada pengujian tanpa beban (tidak tersambung accumulator) pada gambar 6 diperlihatkan penginjakan pada roda depan sepeda motor, pengukuran tegangan generator sebesar 15,71 V.

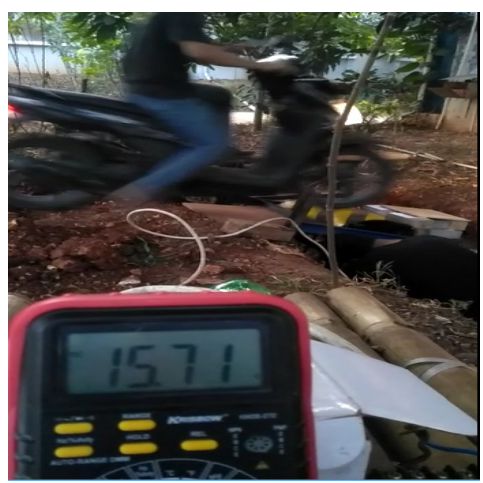

Gambar 6. Penginjakan Pada Roda Depan

Sedangkan pada pengujian berikutnya untuk roda belakang sepeda motor diperlihatkan gambar 7 , pengukuran tegangan generator sebesar $34,41 \mathrm{~V}$.

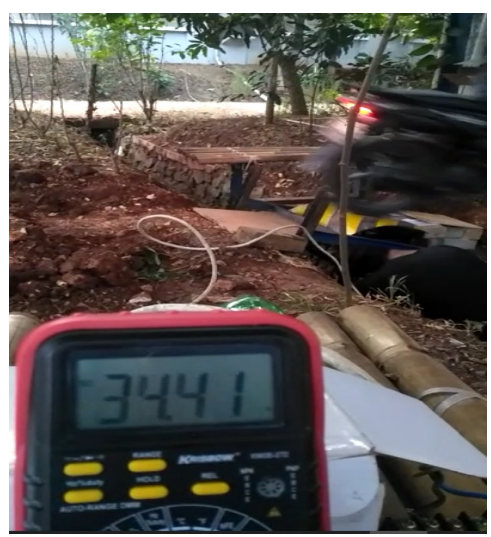

Gambar 7. Penginjakan Pada Roda Depan

\section{HASIL DAN PEMBAHASAN}

Pengambilan data pengujian dilakukan yakni penginjakan pada roda depan saja yang merupakan indikasi awal asupan minimal untuk accumulator sebagai source energi listrik terlihat pada tabel 1.

Tabel 1. Pembangkitan tegangan

\begin{tabular}{lccc}
\hline $\begin{array}{c}\text { Penginjakan Roda } \\
\text { Depan }\end{array}$ & $\begin{array}{c}\text { Tegangan Generator DC } \\
(\boldsymbol{V})\end{array}$ & $\begin{array}{c}\text { Tegangan Setelah } \\
\text { Buckboost }(\boldsymbol{V})\end{array}$ & $\begin{array}{c}\text { Tegangan } \\
\text { Accumulator }(\boldsymbol{V})\end{array}$ \\
\hline Pertama & 1,55 & 13,05 & 8,10 \\
Kedua & 1,20 & 10,08 & 8,10 \\
Ketiga & 1,80 & 15,12 & 8,15 \\
Keempat & 1,90 & 15,96 & 8,20 \\
Kelima & 2,20 & 18,48 & 8,26 \\
Rerata $=$ & $\mathbf{1 , 7 3}$ & $\mathbf{1 4 , 5 4}$ & $\mathbf{8 , 1 6}$ \\
\hline
\end{tabular}

Pengujian yang diperlihatkan pada gambar 8 bahwa penginjakan roda depan dilakukan sebanyak 5 (lima) kali. Penginjakan pertama tegangan generator sebesar 1,55 V kemudian dinaikkan menggunakan 
modul buckboost dihasilkan tegangan 13,05 V. Setelah dinaikkan tegangan tersebut dihubungkan ke accumulator dengan tegangan terukur sebesar $8,10 \mathrm{~V}$. Selanjutnya penginjakan kedua, tegangan generator sebesar $1,20 \mathrm{~V}$, kemudian dengan menggunakan modul buckboost tegangan yang dihasilkan menjadi sebesar 10,08 V, dan dihubungkan pada accumulator dihasilkan tegangan sebesar $8,10 \mathrm{~V}$.

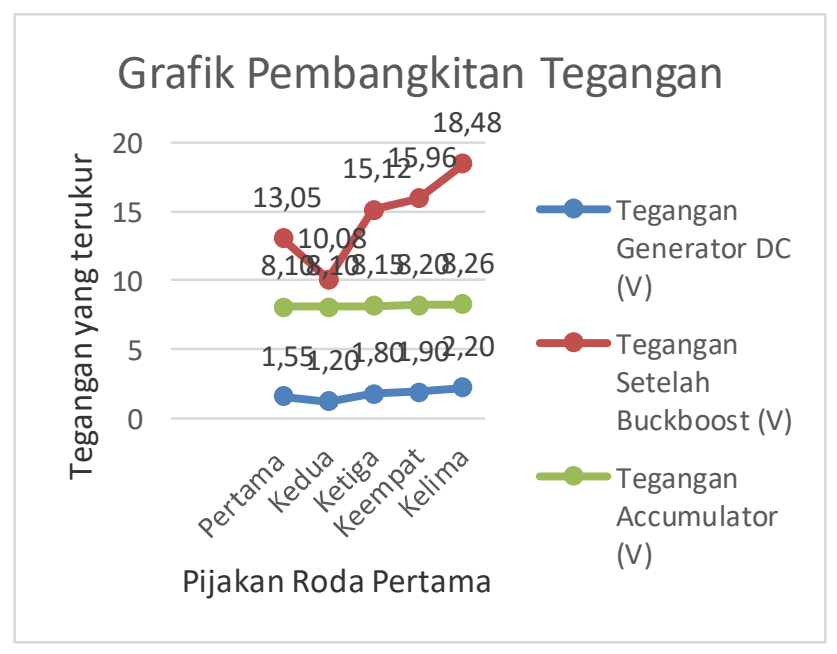

Gambar 8. Grafik Pembangkitan Tegangan

\section{KESIMPULAN}

Hasil pengujian didapatkan keluaran tegangan rata-rata pada generator sebesar $1,73 \mathrm{~V}$, kemudian keluaran tegangan tersebut sebagai inputan pada rangkaian modul buckboost dan didapatkan tegangan rata-rata sebesar 14,54 V. Setelah dinaikkan tegangan yang terhubung pada accumulator dengan tegangan rata-rata sebesar $8,10 \mathrm{~V}$.

\section{UCAPAN TERIMA KASIH}

Peneliti apresiasikan ucapan terima kasih ditujukan kepada pihak yang telah mendanai Penelitian Dosen Pemula (PDP) tahun anggaran 2018 dengan tahun pendanaan 2019 : DIREKTORAT JENDERAL PENGUATAN RISET DAN PENGEMBANGAN dengan Surat Keputusan Nomor : 7/E/KPT/2019 dan Nomor : 110/SP2H/LT/DRPM/2019 ; dan Lembaga Layanan Pendidikan Tinggi Wilayah IV dengan Kontrak Nomor : 2803/L4/PP/2019 ; serta Lembaga Penelitian dan Pengabdian Masyarakat (LPPM) dengan Kontrak Nomor : 026/LPPMPEI/VII/2019.

\section{DAFTAR PUSTAKA}

[1] Ciptian Weried Prianda, 2012. Rancang Bangun Electrical System pada Speedbump Pembangkit Daya, Jurusan Teknik Elektronika, Politeknik Elektronika Negeri Surabaya.

[2] D. Garcia-Pozuelo, A. Gauchia, E. Olmeda, and V. Diaz. 2014. Bump Modeling and Vehicle Vertical Dynamics Prediction, Adv. Mech. Eng., vol. 2014,1-10.

[3] P. Taylor, T. Abiola, O. Salau, A. O. Adeyefa, and S. A. Oke. 2014. Vehicle speed control using road bumps," Transport, Vol XIX, No 3, 130-136.

[4] Nugroho A A. 2016. "Perancangan dan Pembuatan Prototype Alat Konversi Energi Mekanik menjadi Energi Listrik di Jalan Raya dengan menggunakan Speed Bump". Fakultas Teknik, Universitas Muhammadiyah Yogyakarta.

[5] Agus Munadi, 2013. Pembangkit Listrik Tenaga Speed bump sebagai Sumber Energi Alternatif, Fakultas Teknik, Teknik Elektro, Universitas Muhammadiyah Surakarta.

[6] Muhammad Khabib Fathoni, 2017. Daur Ulang Energi Kinetik dari Polisi Tidur (Speed bump) untuk Penghasil Listrik, Fakultas Ilmu Terapan, Universitas Telkom.

[7] Jihan Zeinyuta Rosafira, 2017. Rancang Bangun Polisi Tidur Penghasil Listrik Bagian Statis, Fakultas Teknik, Universitas Jember.

[8] Andhi Kusumo, 2018. Rancang Bangun Speed bump sebagai Pembangkit Listrik, Program Studi Teknik Mesin Industri, ATMI Cikarang.

[9] Muhammad Jaffar Al Faruqi, 2016. Rancang Bangun Pembangkit Listrik Speedbump sebagai Energi Alternatif, Jurusan Teknik Mesin, Universitas Negeri Padang. 